This item was submitted to Loughborough's Research Repository by the author.

Items in Figshare are protected by copyright, with all rights reserved, unless otherwise indicated.

\title{
Future trends in photocatalysis for environmental applications
}

PLEASE CITE THE PUBLISHED VERSION

https://doi.org/10.1016/j.jhazmat.2019.03.073

PUBLISHER

Elsevier

VERSION

AM (Accepted Manuscript)

PUBLISHER STATEMENT

This paper was accepted for publication in the journal Journal of Hazardous Materials and the definitive published version is available at https://doi.org/10.1016/j.jhazmat.2019.03.073.

\section{LICENCE}

CC BY-NC-ND 4.0

\section{REPOSITORY RECORD}

Vilar, Vitor J.P., Dionysios D. Dionysiou, Ricardo Torres-Palma, Sixto Malato, and Gianluca Li-Puma. 2019. "Future Trends in Photocatalysis for Environmental Applications". Loughborough University. https://hdl.handle.net/2134/37948. 
Title: Future Trends in Photocatalysis for Environmental Applications

Authors: Vítor J.P. Vilar ${ }^{1}$, Dionysios D. Dionysiou ${ }^{2}$, Ricardo Torres-Palma ${ }^{3}$, Sixto Malato $^{4}$, Gianluca Li Puma ${ }^{5}$

${ }^{1}$ Laboratory of Separation and Reaction Engineering - Laboratory of Catalysis and Materials (LSRE-LCM), Departamento de Engenharia Química, Faculdade de Engenharia, Universidade do Porto, Rua Dr. Roberto Frias, 4200-465 Porto, Portugal (email: vilar@fe.up.pt)

${ }^{2}$ Environmental Engineering and Science Program, Department of Chemical and Environmental Engineering, 705 Engineering Research Center, University of Cincinnati, Cincinnati, OH 45221-0012, USA (e-mail: dionysios.d.dionysiou@uc.edu)

${ }^{3}$ Grupo de Investigación en Remediación Ambiental y Biocatálisis (GIRAB), Instituto de Química, Facultad de Ciencias Exactas y Naturales, Universidad de Antioquia UdeA, Calle 70 No. 52-21, Medellín, Colombia (email: ricardo.torres@udea.edu.co) ${ }^{4}$ Plataforma Solar de Almería, Carretera Senés Km 4, Tabernas (Almería) 04200, Spain (e-mail: sixto.malato@psa.es)

${ }^{5}$ Environmental Nanocatalysis and Photoreaction Engineering, Department of Chemical Engineering, Loughborough University, Loughborough LE11 3TU, United Kingdom (email: g.lipuma@lboro.ac.uk) 
Technological innovation in the treatment of contaminated liquid and gaseous streams is expected to be a key factor in securing a clean and sustainable environment. Innovative treatment concepts encompassing a small footprint and environmental impact has stimulated the scientific and industrial community.

This special thematic issue of Journal of Hazardous Materials collects scientific studies concerning novel materials, processes and concepts which have been applied to solve realistic environmental problems, including real environmental matrices, contaminated groundwater, surface water, wastewater and contaminated air. The elimination of residues of contaminants of emerging concern remaining in the effluents of conventional wastewater treatment processes is discussed in many studies in this special issue. Examples include: i) novel photocatalysts with high visible light activity for water depollution and $\mathrm{CO}_{2}$ photoreduction; ii) catalytic nanosorbents (e.g., Metal Organic Frameworks-MOFs) for sorption and oxidation of contaminants; iii) strategies to operate iron based advanced oxidation/reduction reactions at mild $\mathrm{pH}$; iv) water disinfection and removal of organic and inorganic contaminants, iv) novel designs and models of photocatalytic reactors, and v) sono- and photoelectrocatalytic systems for the removal of contaminants of emerging concern.

The guest editors would like to thank all the authors for the innovative scientific contributions presented in this special issue of Journal of Hazardous Materials, as well as the reviewers whose comments and suggestions were extremely important to achieve a collection of high-quality papers.

We also thank the lead JHM Editor, Prof. Gianluca Li Puma, of this special edition and the editorial assistants Zheng Amber, Iswarya Samikannu, and Chen Lin for their assistance/help/support in the preparation of this special edition.

Vítor J.P. Vilar wishes to thank the FCT Investigator 2013 Programme (IF/00273/2013) and the financial resources provided by Associate Laboratory LSRE-LCM UID/EQU/50020/2019 - funded by national funds through FCT/MCTES (PIDDAC). Ricardo A. Torres-Palma wants to thank Universidad de Antioquia UdeA through Programa de Sostenibilidad and COLCIENCIAS through the project "Remoción de
Commented [DDD1]: OK but since Gianluca is one of the authors of the editorial needs to be revised

Commented [DDD2]: We also thank the editorial assistants Zheng Amber, Iswarya Samikannu, and Chen Lin for their assistance/help/support in the preparation of this special edition in coordination of the lead JHM Editor, Prof. Gianluca Li Puma. 
antibióticos y bacterias resistentes en aguas residuales hospitalarias empleando tecnologías avanzadas de oxidación”, Project No. 111577757323 (Convocatoria No. 777-

2017). Sixto Malato wishes to thank the Spanish Ministry of Economy and Competitiveness for funding under the ECOSAFEFARMING Project (International Joint Programming Actions, reference: PCIN-2017-005) and 2016 Water and FACCE JPIs Joint Call. Dionysios D. Dionysiou also acknowledges support from the University of Cincinnati through a UNESCO co-Chair Professor position on "Water Access and Sustainability" and the Herman Schneider Professorship in the College of Engineering and Applied Sciences. 


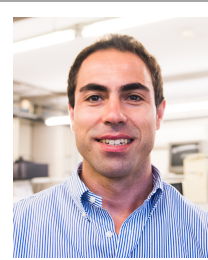

Dr. Vítor Jorge Pais Vilar

vilar@fe.up.pt

Faculty of Engineering University of Porto

Portugal

Vitor J.P. Vilar was born in Miragaia, Porto, Portugal in April 1978. He is principa researcher in the Laboratory of Separation and Reaction Engineering-Laboratory of Catalysis and Materials (LSRE-LCM), Faculty of Engineering, University of Porto (FEUP). He received the graduation in Chemical Engineering in 2001 and the Ph.D. in Chemical Engineering in 2006 at FEUP. In 2014, he was awarded a three-year "Special Visiting Researcher" grant, at the Federal University of Santa Catarina, Brazil, sponsored by the Brazilian Ciência Sem Fronteiras program. He is currently one of the editors of the Environmental Science and Pollution Research (ESPR) Journal (Springer) and Guest editor of the Science of the Total Environment (STOTEN) Journal (Elsevier). He has participated as a committee member or as program chair in nine international conferences on environmental engineering, delivering 38 plenary/keynote/nvited lectures at international conferences and scientific institutions. He is member of the European Ph.D. School on AOPs and president of the Iberoamerican Conference on Advanced Oxidation Technologies (CIPOA)

$\mathrm{He}$ is the author and co-author of more than 400 scientific publications, including 3 conference books, 10 book chapters, 5 editorials, 170 papers in peer-reviewed international scientific periodicals ( $h$-index: 37 and $>4400$ citations), 8 papers in national scientific periodicals, more than 220 contributions in conference proceeding and a co-inventor of 2 patents, receiving 8 prizes in total. He has been participating actively in different projects ( 5 international, 16 national R\&D projects and 3 contrac with private companies) that has granted research funds exceeding 4 million euros. $\mathrm{He}$ has also participated as evaluator of national/international research projects (UEFISCDI, FCT, CNPq, CONICYT, WaterJPI).

His main research interests focus in environmental assessment and monitoring of surface waters and environmental friendly technologies for pollution control, particularly in the application of AOPs, EAOPs, ozonalion and membranes processes or water and air treatment, integration of physical, chemical, biological an membrane processes for the treatment of recalctrant wastewaters, valorisation of natural materials for separation and recovery of heavy metals, oil and grease, so remediation, process integration \& intensification, water/waste reuse and recycling \& valorisation

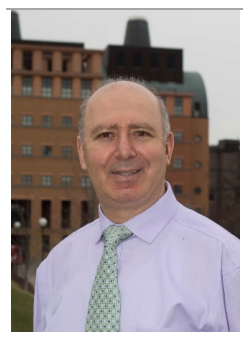

Prof. Dionysios (Dion) D. Dionysiou

dionysios.d.dionysiou@uc.edu

USA

Dr. Dionysios (Dion) D. Dionysiou is currently a Professor of Environmental Engineering and Science Program at the University of Cincinnati. He teaches courses and performs research in the areas of drinking water quality and treatment, advanced unit operations for water treatment, advanced oxidation technologies and nanotechnologies, and physical-chemical processes for water quality control. He has received funding from NSF, US EPA, NASA, NOAA/CICEET, USGS, USDA, Ohio Sea Grant, USAID, and DuPont. He is currently one of the editors of Chemica Engineering Journal and Editor-in-Chief of the Journal of Environmental Engineering (ASCE). He is a member of the Editorial Boards of several other journals. He served as Editor-in-Chief of the Journal of Advanced Oxidation Technologies from January 1, 2008 to December 31, 2017. Dr. Dionysiou is the author or co-author of over 400 refereed journal publications, over 86 conference proceedings, 32 book chapter publications, 28 editorials, and more than 650 presentations. He has edited/co-edited 6 books on water quality, water reuse, ferrates, and photocatalysis. He is currently co-editing a book on harmful algal blooms. Dr. Dionysiou's work received ove 30,000 citations with an $\mathrm{H}$ factor of 91 (Google Scholar). He is a Highly Cited Researcher (in engineering based on Clarivate Analytics, Web of Science, 2018 and in Environmental Science and Engineering and Chemical Engineering based of Shanghai Ranking's Global Ranking of Academic Subjects by Elsevier, 2016).

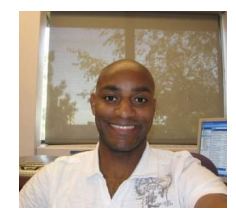

Prof. Ricardo A. Torres-Palma

ricardo.torres@udea.edu.co

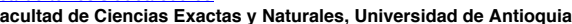

Colombia

Ricardo A. Torres-Palma is graduated in Chemistry and Master in Chemistry by Universidad del Valle, Colombia. He received the PhD in Chemistry from the Universidad del Valle, Colombia. He received the PhD in Chemistry from the Engineering and Applied Chemistry at the University of Toronto (Canada). He is Senior Researcher according to Colciencias (Colombia) and teader of the Research 


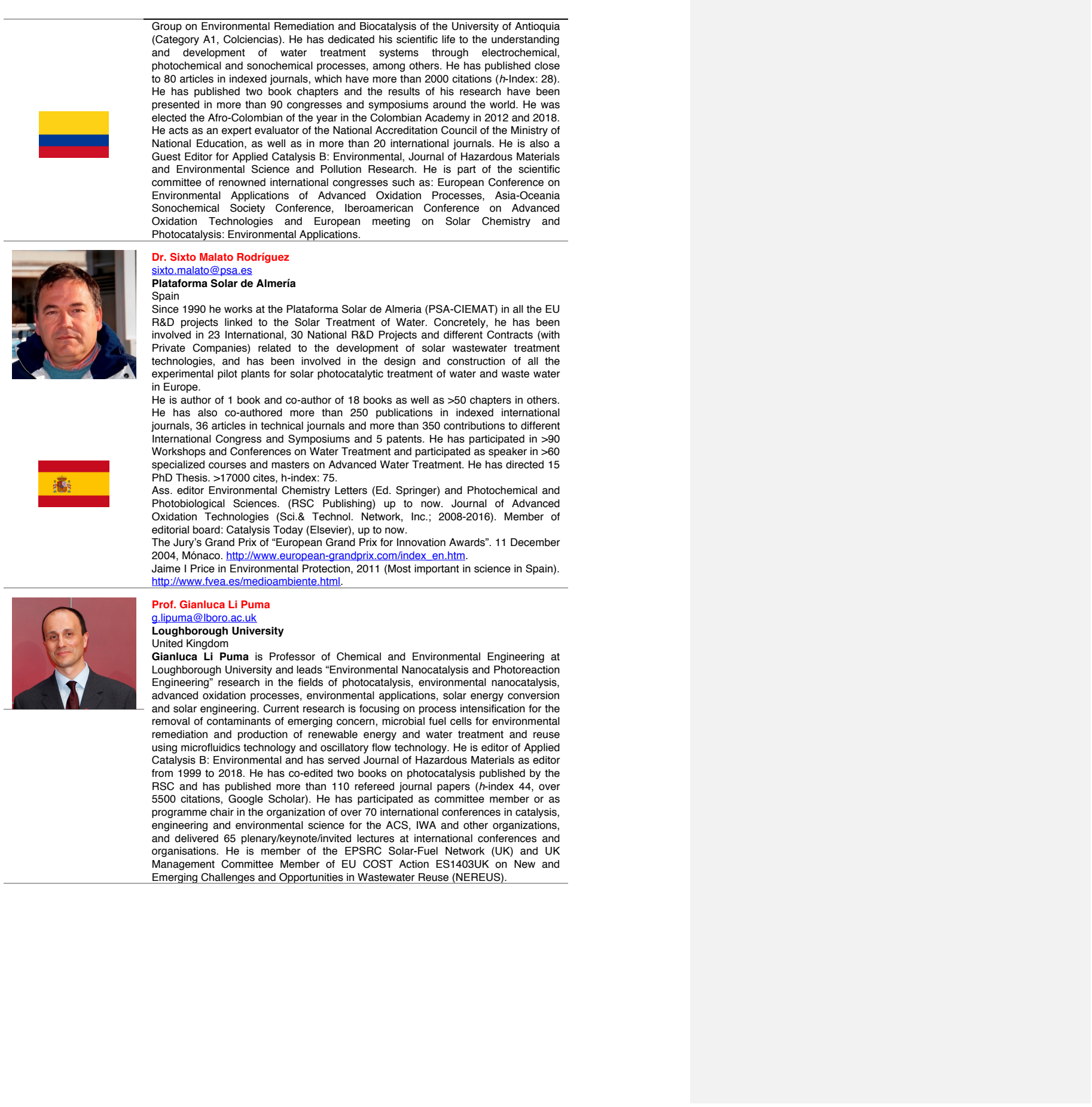

